\title{
Effect of nalbuphine on patient controlled intravenous analgesia after radical resection of colon cancer
}

\author{
QI JIANG ${ }^{1 *}$, RONGFANG ZHANG ${ }^{1^{*}}$ and TAO LIU ${ }^{2}$ \\ ${ }^{1}$ Department of Anesthesiology, Xiang Yang No. 1 People's Hospital, Hubei University of Medicine; \\ ${ }^{2}$ Department of Anesthesiology, Xiangyang Central Hospital, Affiliated Hospital of Hubei University of Arts and Science, \\ Xiangyang, Hubei 441000, P.R. China
}

Received July 12, 2019; Accepted September 11, 2019

DOI: $10.3892 / \mathrm{ol} .2020 .11259$

\begin{abstract}
Effect of nalbuphine on patient-controlled intravenous analgesia (PCIA) after radical resection of colon cancer was explored. Retrospective analyses of 100 patients who underwent elective laparoscopic radical resection of colon cancer in Xiang Yang No. 1 People's Hospital, Hubei University of Medicine from June 2014 to December 2016 were made. Forty-seven patients were treated with nalbuphine as experimental group and 53 cases were treated with morphine as control group. All patients received PCIA after surgery. According to visual analogue scale (VAS), pain degree at 2, 4, 8, 12 and $24 \mathrm{~h}$ after surgery, total dosage of analgesia pump, total times and effective times of pressing were evaluated. Analgesic satisfaction rate, and adverse reactions such as nausea, vomiting, dizziness and headache at the same time were observed and recorded. The postoperative VAS in the experimental group was evidently lower than that in the control group $(\mathrm{P}<0.05)$ at 8,12 and $24 \mathrm{~h}$ after surgery, which was statistically significant. There was no significant difference in postoperative VAS between experimental group and control group at 2 and $4 \mathrm{~h}$ after surgery $(\mathrm{P}>0.05)$. The incidence of adverse reactions to nausea and vomiting in the experimental group was low. There was no significant difference in the total dosage of analgesia pump, total times and effective times of pressing and analgesic satisfaction rate ( $P>0.05)$. After laparoscopic radical resection of colon cancer, nalbuphine is effective in PCIA, with low incidence of adverse reactions and high safety.
\end{abstract}

Correspondence to: Dr Tao Liu, Department of Anesthesiology, Xiangyang Central Hospital, Affiliated Hospital of Hubei University of Arts and Science, 136 Jingzhou Street, Xiangyang, Hubei 441000, P.R. China

E-mail: tbm4e2@163.com

${ }^{*}$ Contributed equally

Key words: nalbuphine, morphine, radical resection of colon cancer, patient controlled intravenous analgesia

\section{Introduction}

With the continuous development of medical technology, 'painless is the right of patients' began to be recognized (1). Clinically, pain has become one of the five major signs of patients, and has been paid increasing attention by medical workers and patients. As one of the most common acute pains, postoperative pain can be seen basically in all postoperative patients. How to deal with the problem safely, quickly and effectively has become a growing concern in medical work and even in the whole society (2). At the same time, endoscope technology has been developed rapidly. Laparoscopic surgery has become more important in the application of surgery because of less trauma and quick recovery. The development of laparoscopic radical resection of colon cancer is also very fast in clinical practice (3). However, postoperative pain is a problem which has not been solved yet. Both physical and psychological suffering can be caused by severe postoperative pain, and it is also the main reason for restricting the patient's movement, which not only increases the risk of postoperative thrombosis, but also may cause metabolic changes that can lead to a series of changes in the whole body system to affect negatively the patient's recovery during the perioperative period $(4,5)$. Therefore, postoperative analgesia is of great significance in clinic.

At present, morphine, fentanyl, sufentanyl and other opioids are commonly used drugs for postoperative analgesia after laparoscopic surgery, all of which are $\mu$ receptor agonists. The limited use of these drugs in clinical practice is due to their adverse reactions such as respiratory depression, nausea and vomiting, excessive sedation and dysuria (6). Nalbuphine is a new kind of analgesic, which belongs to opioids. Its strong spinal sedative effect is mainly through activation of $\kappa$ receptor, which is a $\kappa$ excitation of opioid receptors $/ \mu$ partial antagonist analgesics, and has no strong effect on $\mu$ receptor. The antagonistic action is because the partial effect of antagonistic drugs is both agonism and antagonism. Adverse reactions of nalbuphine such as nausea and vomiting, drowsiness, headache, dizziness, urinary retention, skin irritation and restlessness, are significantly lower than those of morphine, fentanyl and other drugs, with mild respiratory inhibition $(7,8)$. In this study, nalbuphine and morphine were applied to postoperative patient-controlled intravenous analgesia (PCIA) to 
compare the analgesic effects and adverse reactions of the two drugs and to discuss the PCIA of nalbuphine in patients with colon cancer after radical operation.

\section{Patients and methods}

Basic information. Retrospective analyses of 100 patients with colon cancer who were treated in Xiang Yang No. 1 People's Hospital, Hubei University of Medicine (Xiang Yang, China) from June 2014 to December 2016 were made. Patients were aged from 35 to 65 years with a body weight range of $51-84 \mathrm{~kg}$, $\mathrm{BMI}<25$, ASA grade II or III. All colon cancer patients had elective laparoscopic colorectal cancer radical surgeries. Forty-seven patients were treated with nalbuphine as the experimental group and 53 cases were treated with morphine as the control group. All patients were treated with PCIA after surgery. There was no significant difference in sex, age, duration of operation and duration of anesthesia between the two groups $(\mathrm{P}>0.05)$ (Table I).

Inclusion and exclusion criteria. Patients with colon cancer diagnosed pathologically and scheduled to undergo laparoscopic radical resection of colon cancer, aged from 35 to 65 years with a body weight range of $51-84 \mathrm{~kg}, \mathrm{BMI}<25$, ASA grade II or III were included. Patients with a history of opioid or alcohol abuse, with allergies to opioids, who had taken or injected opioid drugs $24 \mathrm{~h}$ before surgery, or not cooperating with the examination, with communication and cognitive disorders were excluded.

The present study was approved by the Ethics Committee of Xiang Yang No. 1 People's Hospital, Hubei University of Medicine. All subjects and their families signed an informed consent and cooperated with medical staff to complete the diagnosis and treatment.

Medications. Sulfentanyl was purchased from Yichang Humanwell Healthcare (Group) Co., Ltd., SFDA approval no. H20054256. Midazolam from Jiangsu Ehwa Pharmaceutical Co., Ltd., SFDA approval no. H20031037. Vecuronium bromide from Chengdu Tiantaishan Pharmaceutical Co., Ltd., SFDA approval no. H20063411. Propofol from Sichuan Guorui Pharmaceutical Co., Ltd., SFDA approval no. H20040079. Flurbiprofen axetil from Beijing Tide Pharmaceutical Co., Ltd., SFDA approval no. H20041508. Oxycodone hydrochloride from NAPP Pharmaceutical SL Ltd., SFDA approval no. J20130142. Pantazosine injection from Beijing Double-Crane Pharmaceutical Co., Ltd., TCM approval no. H10983218. Tramadol hydrochloride injection from German Hexal AG, ICP approval no. H20070150. Dolasetron from Liaoning Haisco Pharmaceutical Co., Ltd., SFDA approval no. H20110068. Nalbuphine Yichang Renfu pharmaceutical Co., Ltd., SFDA approval no. H20130127. Morphine from Northeast Pharmaceutical Group Shenyang first Pharmaceutical Co., Ltd., SFDA approval no. H21022436.

Method. Preoperative routine prohibition of diet. A conventional intravenous access was obtained after the patient entered the operation room, and the heart rate, pulse oxygen saturation and blood pressure were detected by a multifunction detector. Sulfentanyl $0.5 \mu \mathrm{g} / \mathrm{kg}$, midazolam $0.04 \mathrm{mg} / \mathrm{kg}$, vecuronium bromide $0.1 \mathrm{mg} / \mathrm{kg}$, propofol $1.5 \mathrm{mg} / \mathrm{kg}$ were used for anesthetic induction. Tracheal intubation and device were used simultaneously to control respiration after muscle relaxation. Continuous intravenous infusion of remifentanil $3-6 \mu \mathrm{g} / \mathrm{kg} / \mathrm{h}$ and propofol $1.5-3.0 \mathrm{mg} / \mathrm{kg} / \mathrm{h}$ by micro pump were used to maintain anesthesia and vecuronium $2-4 \mathrm{mg}$ was given to maintain muscle relaxation according to the needs during operation. No muscle relaxants before $30 \mathrm{~min}$ was completed. No anesthetic after closing the peritoneum, flurbiprofen axetil $1 \mathrm{mg} / \mathrm{kg}$, oxycodone hydrochloride $0.1 \mathrm{mg} / \mathrm{kg}$, pantazosine injection $0.5 \mathrm{mg} / \mathrm{kg}$. Tramadol hydrochloride injection $1 \mathrm{mg} / \mathrm{kg}$, dolasetron $0.3 \mathrm{mg} / \mathrm{kg}$ were infused intravenously. Larynx mask could be removed and the patient return to the ward when fully awake after spontaneous respiration gradually recovering to more than $6 \mathrm{ml} / \mathrm{kg}$ of tidal volume (VT), respiratory rate (RR) to more than 10 times/min, and recovery of consciousness, swallowing reflex and choking cough reflex. The analgesic pump in the experimental group was composed of nalbuphine $90 \mathrm{mg}$ and saline $100 \mathrm{ml}$; the control group was morphine $90 \mathrm{mg}$ and saline $100 \mathrm{ml}$; velocity of background infusion was both $2 \mathrm{ml} / \mathrm{h}$, patient controlled analgesia (PCA) were both $2 \mathrm{ml}$, and the locking duration was $10 \mathrm{~min}$ for both.

Outcome measures. According to postoperative visual analogue scale (VAS) the pain score was evaluated at 2, 4, 8,12 and $24 \mathrm{~h}$, respectively, after surgery. Total dose of analgesic pump, total times and effective times of pressing were recorded, and postoperative pain grading and analgesic satisfaction rate were evaluated. Adverse reactions such as nausea, vomiting, drowsiness, dizziness and headache, respiratory depression and urinary retention were recorded. The negative emotion scores of the two groups were compared after 3 days of analgesia.

VAS method. Visual analogues scale (VAS) (9) evaluates the analgesic effect by visual analogue score. Judging criteria: totally painless, 0 grade, mild pain, 1-3 grades, moderate pain, 4-7 grades, and severe pain, 8-10 grades. VAS classification method: Level 1, no marked pain. Level 2, painful but in tolerable range, no effect on sleep, life is basically normal. Level 3 , the pain is aggravated, unbearable, requiring analgesia, and sleep is affected. Level 4 , severe pain, unbearable, requiring analgesia, and sleep is seriously affected, accompanied by autonomic nervous disorders or passive posture. The satisfaction rate of analgesia is equal to (levels $1+2)$ / total number of patients $\times 100 \%$.

Statistical analysis. The data was analyzed by SPSS17.0 (SPSS, Inc., Chicago, IL, USA) statistical software, and the measurement data was represented by mean \pm standard deviation. Single factor analysis of variance (ANOVA) was used for multigroup comparisons with Dunnett's post hoc test, independent sample t-test for comparison between two groups, and $\chi^{2}$ test for enumeration data. $\mathrm{P}<0.05$ was considered as statistically significant.

\section{Results}

Comparison of VAS scores between two groups at different time-points. The VAS of experimental group at 8, 12 and $24 \mathrm{~h}$ 
Table I. General information of patients in two groups.

\begin{tabular}{|c|c|c|c|c|}
\hline Factors & $\begin{array}{l}\text { Experimental group } \\
\qquad(\mathrm{n}=47)\end{array}$ & $\begin{array}{l}\text { Control group } \\
\qquad(\mathrm{n}=53)\end{array}$ & Statistic & P-value \\
\hline Age, n (\%) & & & 0.036 & 0.851 \\
\hline$\leq 50$ & $16(34.04)$ & $19(35.85)$ & & \\
\hline$>50$ & $31(65.96)$ & $34(64.15)$ & & \\
\hline Sex, n (\%) & & & 0.040 & 0.841 \\
\hline Male & $24(51.06)$ & $26(49.06)$ & & \\
\hline Female & $23(48.94)$ & $27(50.94)$ & & \\
\hline ASA classification, n (\%) & & & 0.134 & 0.715 \\
\hline Grade II & $24(51.06)$ & $29(54.72)$ & & \\
\hline Grade III & $23(48.94)$ & $24(45.28)$ & & \\
\hline BMI $\left(\mathrm{kg} / \mathrm{m}^{2}\right), \mathrm{n}(\%)$ & & & 0.001 & 0.971 \\
\hline$\leq 21$ & $25(53.19)$ & $28(52.83)$ & & \\
\hline$>21$ & $22(46.81)$ & $25(47.17)$ & & \\
\hline Tumor location, n (\%) & & & 0.004 & 0.952 \\
\hline Left colon & $21(44.68)$ & $24(45.28)$ & & \\
\hline Right colon & $26(55.32)$ & $29(54.72)$ & & \\
\hline Tumor maximum diameter $(\mathrm{cm}), \mathrm{n}(\%)$ & & & 0.097 & 0.756 \\
\hline$\leq 5$ & $12(25.53)$ & $15(28.30)$ & & \\
\hline$>5$ & $35(74.47)$ & $38(71.70)$ & & \\
\hline \multicolumn{5}{|l|}{ Pathological type, n (\%) } \\
\hline Adenocarcinoma & $14(29.79)$ & $16(30.19)$ & 0.048 & 0.826 \\
\hline Colloid carcinoma & $16(34.04)$ & $19(35.85)$ & 0.036 & 0.850 \\
\hline Undifferentiated carcinoma & $17(36.17)$ & $18(33.96)$ & 0.053 & 0.817 \\
\hline Stagings, n (\%) & & & 0.655 & 0.418 \\
\hline I-II & $37(78.72)$ & $38(71.70)$ & & \\
\hline III-IV & $10(21.28)$ & $15(28.30)$ & & \\
\hline \multicolumn{5}{|l|}{ Negative emotion score } \\
\hline SAS & $49.61 \pm 8.72$ & $50.07 \pm 8.65$ & 0.264 & 0.792 \\
\hline SDS & $50.23 \pm 8.61$ & $50.19 \pm 8.24$ & 0.024 & 0.981 \\
\hline Anesthesia duration (min) & $130.78 \pm 41.21$ & $129.69 \pm 40.17$ & 0.134 & 0.894 \\
\hline Operation duration (min) & $96.88 \pm 12.98$ & $97.67 \pm 13.12$ & 0.303 & 0.763 \\
\hline
\end{tabular}

after surgery were significantly lower than the control group, and the difference was statistically significant $(\mathrm{P}<0.05)$. While there was no significant difference between two groups at 2 and $4 \mathrm{~h}$ after surgery, and the difference was not statistically significant $(\mathrm{P}>0.05)$ (Table II).

Comparison of the total dosage of analgesic pump, total times and effective times of pressing between the two groups. There was no statistically significant difference between the experimental and the control group in the total dosage of analgesic pump, total times and effective times of pressing $(\mathrm{P}>0.05)$ (Table III).

Comparison of analgesic satisfaction rate between two groups. The analgesic satisfaction rate was $95.75 \%$ in the experimental group and $92.45 \%$ in the control group. There was no significant difference in the analgesic satisfaction rate between the experimental group and the control group, which was not statistically significant $(\mathrm{P}>0.05)$ (Table IV).
Table II. Comparison of VAS scores between two groups at different time-points.

\begin{tabular}{lccrr}
\hline $\begin{array}{l}\text { Time } \\
\text { (h) }\end{array}$ & $\begin{array}{l}\text { Experimental } \\
\text { group }(\mathrm{n}=47)\end{array}$ & $\begin{array}{c}\text { Control } \\
\text { group }(\mathrm{n}=53)\end{array}$ & t value & P-value \\
\hline 2 & $0.33 \pm 0.41$ & $0.39 \pm 0.47$ & 0.680 & 0.498 \\
4 & $1.62 \pm 0.58$ & $1.49 \pm 0.61$ & 1.092 & 0.278 \\
8 & $2.81 \pm 0.57^{\mathrm{a}}$ & $3.51 \pm 0.54^{\mathrm{a}}$ & 6.304 & $<0.001$ \\
12 & $3.17 \pm 0.52^{\mathrm{a}}$ & $4.18 \pm 0.55^{\mathrm{a}}$ & 9.436 & $<0.001$ \\
24 & $3.22 \pm 0.66^{\mathrm{a}}$ & $4.47 \pm 0.49^{\mathrm{a}}$ & 10.751 & $<0.001$ \\
\hline
\end{tabular}

${ }^{\text {a }} \mathrm{P}<0.05$ compared with the control group. VAS, visual analogue scale.

Comparison of the incidence of adverse reactions between two groups. The incidence of adverse reactions was $14.91 \%$ in the experimental group, which was significantly lower than the 
Table III. Comparison of the total dosage of analgesic pump and times of pressing between the two groups.

\begin{tabular}{lcccc}
\hline Factors & $\begin{array}{c}\text { Experimental } \\
\text { group }(\mathrm{n}=47)\end{array}$ & $\begin{array}{c}\text { Control } \\
\text { group }(\mathrm{n}=53)\end{array}$ & t value & P-value \\
\hline Total dosage of analgesic pump $(\mathrm{ml})$ & $62.12 \pm 9.88$ & $60.86 \pm 10.23$ & 0.626 & 0.533 \\
Total pressing times & $2.89 \pm 0.91$ & $2.71 \pm 1.16$ & 0.859 & 0.392 \\
Effective pressing times & $2.35 \pm 0.32$ & $2.21 \pm 0.78$ & 1.174 & 0.243 \\
\hline
\end{tabular}

Table IV. Comparison of analgesic satisfaction rate between two groups (n, \%).

\begin{tabular}{lcccc}
\hline Classification & $\begin{array}{c}\text { Experimental group } \\
(\mathrm{n}=47)\end{array}$ & $\begin{array}{c}\text { Control group } \\
(\mathrm{n}=53)\end{array}$ & $\chi^{2}$ value & P-value \\
\hline Level 1 & $39(82.98)$ & $37(69.81)$ & 0.219 & 0.240 \\
Level 2 & $6(12.77)$ & $12(22.64)$ & 0.065 & 0.799 \\
Level 3 & $2(4.25)$ & $4(7.55)$ & 0.154 & 0.695 \\
Level 4 & 0 & 0 & - & - \\
Analgesic satisfaction rate (\%) & 95.75 & 92.45 & 0.211 & 0.646 \\
\hline
\end{tabular}

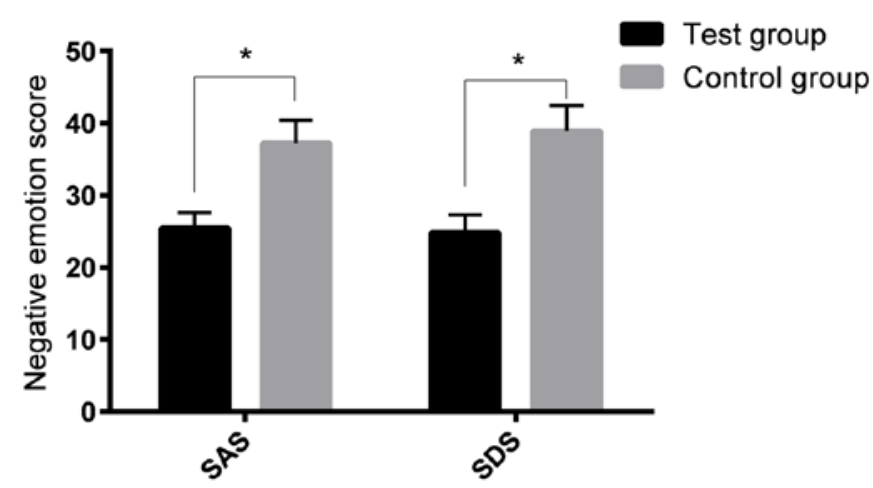

Figure 1. Negative emotion scores of the two groups after 3 days of analgesia. SAS score and SDS score of the experimental group 3 days after analgesia were significantly lower than those of the control group $(\mathrm{P}<0.05)$. ${ }^{*} \mathrm{P}<0.05$.

$54.71 \%$ of the control group. The difference was statistically significant $(\mathrm{P}<0.05)$. No respiratory inhibition was found in any patient, and the adverse reactions improved after treatment (Table V).

Negative emotion scores of the two groups after 3 days of analgesia. The SAS score and SDS score of the experimental group were $25.46 \pm 2.13$ and $24.87 \pm 2.43$, respectively, on the 3rd day after analgesia. The SAS and SDS score of the control group were $37.26 \pm 3.19$ and $38.92 \pm 3.54$, respectively, on the 3rd day after analgesia. The SAS score and SDS score of the experimental group were significantly lower than those of the control group $(\mathrm{P}<0.05)$ (Fig. 1).

\section{Discussion}

In recent years, postoperative analgesia after laparoscopic surgery has been paid increasing attention. Perfect postoperative analgesia can not only improve the quality of life of patients during perioperative period, but also reduce the occurrence of adverse reactions and be beneficial to the recovery of patients, which is in line with the concept of fast track surgery (FTS) (10). Postoperative analgesia has been developed as a professional technique due to its necessity in perioperative period (11). Good analgesic treatment can alleviate the adverse reactions and stress reactions caused by pain and drugs in the nervous, endocrine and immune system of patients, and it is also conducive to the rapid and steady recovery of the body (12). Therefore, many medical workers have been carrying out clinical research, analgesic methods and drug exploration. Nalbuphine, one of the mixed agitated antagonistis, is a $\kappa$ excitation of opioid receptors/ $\mu$ partial antagonist analgesics. The analgesic effect of spinal cord mainly depends on the activation of $\kappa$ receptor. Its analgesic effect is similar to that of morphine. It has two effects, excitatory and antagonistic but has a weak effect on $\mu$ receptor. It can antagonize partial effects of agonists. Nalbuphine can also reduce adverse effects such as nausea, vomiting, drowsiness, skin pruritus, urinary retention, and respiratory inhibition and addiction were lower (13). The pharmacological effect of this kind of medicine is unique, which is suitable for the requirement of comfortable medical treatment and the concept of rapid postoperative recovery. Although nalbuphine and morphine can be used alone to obtain a commendable analgesic effect in postoperative intravenous analgesia, nalbuphine has the advantages of quicker effect, longer effective drug duration, lower addiction, and relatively higher safety than opioids, such as morphine. Its clinical application of postoperative analgesia is more and more extensive (14).

In this study, the analysis of PCIA of patients with nalbuphine and morphine after radical resection of colon cancer showed that all patients received good analgesia within $4 \mathrm{~h}$ after surgery and there was no significant difference in VAS score between the experimental and the control group within $4 \mathrm{~h}$ after operation $(\mathrm{P}>0.05)$. While the VAS score of the patients in the experimental group was significantly lower than that in the control group at 8,12 and $24 \mathrm{~h}$ after 
Table V. Comparison of the incidence of adverse reactions between two groups (n, \%).

\begin{tabular}{lccc}
\hline Classification & $\begin{array}{c}\text { Experimental group } \\
(\mathrm{n}=47)\end{array}$ & $\begin{array}{c}\text { Control group } \\
(\mathrm{n}=53)\end{array}$ & $\chi^{2}$ value \\
\hline Nausea & $2(4.26)$ & $5(9.43)$ & 1.079 \\
Vomiting & $2(4.26)$ & $6(11.32)$ & 1.690 \\
Drowsiness & $1(2.13)$ & $5(9.43)$ & 2.431 \\
Dizziness and headache & $2(4.26)$ & $6(11.32)$ & 1.690 \\
Respiratory depression & 0 & $0-299$ & 0.194 \\
Urinary retention & 0 & $7(13.21)$ & 6.119 \\
Total incidence $(\%)$ & 14.91 & 54.71 & 0.194 \\
\hline
\end{tabular}

surgery, and the score was statistically significant $(\mathrm{P}<0.05)$, which indicated that the analgesic effect of nalbuphine was more satisfactory at $8 \mathrm{~h}$ after operation. However, there was no significant difference in the satisfactory rate of analgesia between the two groups, suggesting that the analgesic effect of the two groups was quite similar. Because the satisfaction rate of pain is based on VRS grade, and VAS score is more accurate than VRS grade, there may be some difference between them. Laparoscopic surgery is more likely to lead to adverse reactions such as nausea and vomiting due to the pressurization of oxygen by mask during induction of general anesthesia, gas entering the digestive tract, or high concentration nitrous oxide diffusing into the intestinal cavity, stimulating gastrointestinal mucosa to produce pneumoperitoneum (15,16). Benz et al (17), Buunen et al (18) found that patients with colon cancer after laparoscopic surgery had a higher incidence of postoperative nausea and vomiting due to surgery, age and other reasons, which means that there is a more stringent requirement for the solution of postoperative labor pain problems. Postoperative analgesia not only relieves the patient's pain, but also minimizes the incidence of related adverse reactions. In this study, the number of patients with nausea and vomiting in the control group was higher than that in experimental group, in which the patients with same symptoms were rare, and almost no symptoms of drowsiness and urinary retention. Part of the antagonistic effects of nalbuphine occurred in $\mu$ receptors, making the incidence of adverse reactions in the experimental group significantly lower than that in morphine group. Because there are few studies on morphine in radical resection of colon cancer, we compared the use of morphine in other operations with our experiments. The study of Beaver et al (19), and Yeh et al (20) found that there was no significant difference in analgesic effect between nalbuphine and morphine in postoperative analgesia of cesarean section, but the adverse reactions such as nausea, vomiting and lethargy occurred less in the nalbuphine group, which was consistent with our findings. There are also studies $(21,22)$ on the relationship between the dosage of morphine and factors. Finally, we found that the negative emotional score of the experimental group after 3 days of analgesia was significantly lower than that of the control group $(\mathrm{P}<0.05)$, suggesting that the reduction of pain may improve the negative emotions of patients. The study of Buhle et al (23) also proved that there was a relationship between pain and emotion.
The analgesic effect of nalbuphine is similar to that of morphine in PCIA after laparoscopic radical resection of colon cancer, but nalbuphine is safer and has less incidence of adverse reactions than morphine. Laparoscopic radical resection of colon cancer can be used as a good choice for postoperative analgesia. Thus, nalbuphine can be used as a good choice for postoperative analgesia in laparoscopic radical resection of colon cancer. In this experiment, the number of specimens included in this study is small, and the possible effects of psychological factors on pain was not evaluated, thus there might be some contingency in the results and further studies are still required.

\section{Acknowledgements}

Not applicable.

\section{Funding}

No funding was received.

\section{Availability of data and materials}

The datasets used and/or analyzed during the present study are available from the corresponding author on reasonable request.

\section{Authors' contributions}

QJ wrote the manuscript. QJ and RZ conceived and designed the study, and collected the data. QJ and TL contributed to observation indexes analysis, revised and approved the manuscript. All authors read and approved the final manuscript.

\section{Ethics approval and consent to participate}

The present study was approved by the Ethics Committee of Xiang Yang No. 1 People's Hospital, Hubei University of Medicine (Xiang Yang, China). All subjects and their families signed an informed consent and cooperated with medical staff to complete the diagnosis and treatment.

\section{Patient consent for publication}

Not applicable. 


\section{Competing interests}

The authors declare that they have no competing interests.

\section{References}

1. Chou R, Gordon DB, de Leon-Casasola OA, Rosenberg JM, Bickler S, Brennan T, Carter T, Cassidy CL, Chittenden EH, Degenhardt E, et al: Management of postoperative pain: A clinical practice guideline from the American pain pociety, the American Society of Regional Anesthesia and Pain Medicine, and the American Society of Anesthesiologists' Committee on regional anesthesia, executive committee, and Administrative Council. J Pain 17: 131-157, 2016.

2. Rawal N: Current issues in postoperative pain management. Eur J Anaesthesiol 33: 160-171, 2016.

3. Stormark K, Søreide K, Søreide JA, Kvaløy JT, Pfeffer F, Eriksen MT, Nedreb $\varnothing$ BS and Kørner H: Nationwide implementation of laparoscopic surgery for colon cancer: Short-term outcomes and long-term survival in a population-based cohort. Surg Endosc 30: 4853-4864, 2016.

4. Pogatzki-Zahn E, Kutschar P, Nestler N and Osterbrink J: A prospective multicentre study to improve postoperative pain: Identification of potentialities and problems. PLoS One 10: e0143508, 2015.

5. Zhou X, Zhang C, Wang M, Yu L and Yan M: Dezocine for preventing postoperative pain: A meta-analysis of randomized controlled trials. PLoS One 10: e0136091, 2015.

6. Wilson NM, Ripsch MS and White FA: Impact of opioid and nonopioid drugs on postsurgical pain management in the rat. Pain Res Treat 2016: 8364762, 2016.

7. Berterame S, Erthal J, Thomas J, Fellner S, Vosse B, Clare P, Hao W, Johnson DT, Mohar A, Pavadia J, et al: Use of and barriers to access to opioid analgesics: A worldwide, regional, and national study. Lancet 387: 1644-1656, 2016.

8. Abdel Shaheed C, Maher CG, Williams KA, Day R and McLachlan AJ: Efficacy, tolerability, and dose-dependent effects of opioid analgesics for low back pain: A systematic review and meta-analysis. JAMA Intern Med 176: 958-968, 2016.

9. Hoemann C, Kandel R, Roberts S, Saris DB, Creemers L, Mainil-Varlet P, Méthot S, Hollander AP and Buschmann MD: International Cartilage Repair Society (ICRS) recommended guidelines for histological endpoints for cartilage repair studies in animal models and clinical trials. Cartilage 2: 153-172, 2011.

10. Wang N, Zhou H, Song X and Wang J: Comparison of oxycodone and sufentanil for patient-controlled intravenous analgesia after laparoscopic radical gastrectomy: A randomized double-blind clinical trial. Anesth Essays Res 10: 557-560, 2016.

11. Ge DJ, Qi B, Tang G and Li JY: Intraoperative dexmedetomidine promotes postoperative analgesia and recovery in patients after abdominal hysterectomy: A double-blind, randomized clinical trial. Sci Rep 6: 21514, 2016.
12. Zhang XK, Chen QH, Wang WX and Hu Q: Evaluation of dexmedetomidine in combination with sufentanil or butorphanol for postoperative analgesia in patients undergoing laparoscopic resection of gastrointestinal tumors: A quasi-experimental trial. Medicine (Baltimore) 95: e5604, 2016.

13. Chen MK, Chau SW, Shen YC, Sun YN, Tseng KY, Long CY, Feng YT and Cheng KI: Dose-dependent attenuation of intravenous nalbuphine on epidural morphine-induced pruritus and analgesia after cesarean delivery. Kaohsiung J Med Sci 30: 248-253, 2014.

14. Chatrath V, Attri JP, Bala A, Khetarpal R, Ahuja D and Kaur S: Epidural nalbuphine for postoperative analgesia in orthopedic surgery. Anesth Essays Res 9: 326-330, 2015.

15. Fried GM, Feldman LS, Vassiliou MC, Fraser SA, Stanbridge D, Ghitulescu G and Andrew CG: Proving the value of simulation in laparoscopic surgery. Ann Surg 240: 518-528, 2004.

16. Buunen M, Veldkamp R, Hop WC, Kuhry E, Jeekel J, Haglind E, Påhlman L, Cuesta MA, Msika S, Morino M, et al; Colon Cancer Laparoscopic or Open Resection Study Group: Survival after laparoscopic surgery versus open surgery for colon cancer: Long-term outcome of a randomised clinical trial. Lancet Oncol 10: 44-52, 2009.

17. Benz S, Barlag H, Gerken M, Fürst A and Klinkhammer-Schalke M: Laparoscopic surgery in patients with colon cancer: A population-based analysis. Surg Endosc 31: 2586-2595, 2017.

18. Buunen M, Veldkamp R, Hop WC, Kuhry E, Jeekel J, Haglind E, Påhlman L, Cuesta MA, Msika S, et al:Survival after laparoscopic surgery versus open surgery for colon cancer: long-term outcome of a randomised clinical trial. Lancet Oncol 10: 44-52, 2009.

19. Beaver WT and Feise GA: A comparison of the analgesic effect of oxymorphone by rectal suppository and intramuscular injection in patients with postoperative pain. J Clin Pharmacol 17: 276-291, 1977.

20. Yeh YC, Lin TF, Chang HC, Chan WS, Wang YP, Lin CJ and Sun WZ: Combination of low-dose nalbuphine and morphine in patient-controlled analgesia decreases incidence of opioid-related side effects. J Formos Med Assoc 108: 548-553, 2009.

21. Minai FN and Khan FA: A comparison of morphine and nalbuphine for intraoperative and postoperative analgesia. J Pak Med Assoc 53: 391-396, 2003.

22. Park JS, Choi GS, Kwak KH, Jung H, Jeon Y, Park S and Yeo J: Effect of local wound infiltration and transversus abdominis plane block on morphine use after laparoscopic colectomy: A nonrandomized, single-blind prospective study. J Surg Res 195: 61-66, 2015.

23. Buhle JT, Kober H, Ochsner KN, Mende-Siedlecki P, Weber J, Hughes BL, Kross E, Atlas LY, McRae K and Wager TD: Common representation of pain and negative emotion in the midbrain periaqueductal gray. Soc Cogn Affect Neurosci 8: 609-616, 2013. 